\title{
FDA draft guidance on compounding animal drugs from bulk drug substances: a commentary
}

\author{
Adel H. Karara
}

\section{Background}

The statement made by Debra Schotik Chan in 2001 (Chan 2001) regarding the regulations for use of bulk drugs in animals being unclear was probably true until last year. In May 2015 FDA issued a draft guidance on compounding animal drugs from bulk drug substances (Guidance for Industry (Draft) (\#230) 2015). The guidance included specific FDA mandated conditions for animal drug compounding for each of: 1) state-licensed pharmacies, 2) licensed veterinarians or 3) outsourcing facilities. Since many pharmacy professionals and pharmaceutical scientists work at outsourcing facilities, this guidance is certainly of importance as it is expected to be finalized in 2016.

The compounding of animal drugs from bulk drug substances results in a new animal drug that must comply with the FD\&C Act's approval and indexing requirements (Steinschneider 2012). FDA has long had a concern regarding the unrestricted compounding of animal drug products as it raises the same concerns as other unapproved animal drugs (Steinschneider 2012). If the compounded drug is for a food-producing animal, it may pose a risk to the animals or humans if unsafe tissue residues should occur or it may be ineffective in the animal (Steinschneider 2012). Also for these products, there is no mandatory reporting to the FDA of adverse events drug experiences (Steinschneider 2012). Additionally, these products may undermine the incentives to develop and submit new animal drug applications to FDA containing data and information to demonstrate that the product is safe, effective, properly manufactured, and accurately labeled (Guidance for Industry (Draft) (\#230) 2015).

Although there has been an increase in the number of approved veterinary products on the market, it is still

\footnotetext{
Correspondence: ahkarara@umes.edu

Department of Pharmaceutical Sciences, School of Pharmacy, University of Maryland Eastern Shore, 11868 Academic Oval, Princess Anne, MD 21853,
} USA

well recognized that extemporaneous drug formulation is essential to provide optimal pharmaceutical care to veterinary patients especially when medications are not available in the desired dosage form. Lack of commercially available products, drug dose adjustment, high cost of finished drug products especially those for certain neoplastic and immune-mediated diseases, ease of administration and flavor compounding to make medication taste better and enhancing compliance are typically the main drivers for veterinary compounding. Under the proposed guidance, FDA does not intend to take action under sections 512(a), 501(a)(5), and 501(a)(2)(B) of the FD\&C Act (FD\&C Act Chapter V) if an outsourcing facility compounds animal drugs from bulk drug substances in accordance with the defined applicable conditions published in the document (Guidance for Industry (Draft) (\#230) 2015).

Key features of the conditions mandated by guidance

- When finalized the document will be populated with a list of bulk drug substances (Appendix A of FDA guidance) for use by outsourcing facilities

- The veterinarian's prescription specifies that the drug is intended to treat the species and condition(s) for which the substance is listed in Appendix A

- The drug is not intended for use in food-producing animals and that it is compounded under cGMP

- Providing FDA with biannual reports on outsourcing activities

- Mandatory reporting to FDA of serious-adverse events

- Adequate labeling of compounded animal drug (Guidance for Industry (Draft) (\#230) 2015).

Appendix A of FDA guidance containing the list of bulk drug substance is probably the center piece of this 
guidance. Public input was sought for nominating bulk drug substances for the list. FDA established a set of criteria that had to be met for a drug candidate to be added to the list. Those criteria included no marketed approved animal drug that can be used as labeled to treat the condition, there is no marketed approved animal or human drug that could be used under section 512(a)(4) or (a)(5) and 21 CFR Part 530 to treat the condition (extralabel use), the drug cannot be compounded from approved animal or human drug, immediate treatment with compounded drug is necessary to avoid animal suffering or death and FDA has not identified a significant safety concern specific to the use of bulk drug substance (Guidance for Industry (Draft) (\#230) 2015). Outsourcing facilities seeking to compound animal drug should be registered under section 503B of the FD\&C act(Guidance for industry 2014). The compounding facility would need to have a prescription from a veterinarian for an individually identified animal patient or an order from veterinarian for veterinarian office use (Guidance for Industry (Draft) (\#230) 2015).

Overall the draft guidance tightens FDA control of compounding animal drugs from bulk drug substances. The new documentation requirements represent added paper work burden on compounding outsourcing facilities, pharmacies and the veterinarian. For the prescribing veterinarian, it will require justification based on clinical evidence in the individually identified animal patient that the compounded drug effect would be different from that of the FDA approved animal or human drug product. That may not be an easy case to make. It is true that if the approved drug dose is too large for the intended animal patient and the dosage form cannot be divided or diluted into the small dose required then that would be a good justification for requiring a compounded drug and expecting a clinical difference from a lower dose (Chan 2001). However, there may be cases where it is difficult to dose the approved formulation in a particular animal. That may be the case especially for cats which are hard to dose in general but also it could be due to the volume of the dose of medication that needs to be smaller, or removing the bitter taste by adding an appealing flavor (Davis 1997). The prescribing veterinarian should provide a statement accompanying the prescription documenting the clinical difference for the individually identified animal patient. Methimazole, a drug commonly used for the treatment of feline hyperthyroidism is available as oral coated tablets. The twicea-day regimen chronic treatment as might be expected can be difficult for the owners of uncooperative animals which has led to the development of transdermal options for drug administration. Results from several clinical studies have shown that while the transdermal gel is not as effective as the oral dosage from it is still a viable alternative in the treatment of feline hyperthyroidism (Lecuyer et al. 2006; Sartor et al. 2004). This represents an opportunity for compounding pharmacies and outsourcing facilities seeking to satisfy an unmet need for veterinary patients. It should also be noted that compounding facilities that are engaged in compounding sterile preparations have to comply with USP Chapter <797> to minimize contamination risks to patients. One new restriction in the guidance deals with compounded drug products for "office use". Under the draft guidance every animal prescription to be compounded from bulk drug substance has to correspond to an individually identified animal patient. Limitations on the amount of compounding done in advance of receipt of a prescription were specified. That amount should not exceed the amount of drug product that the state-licensed pharmacy compounded based on a patient-specific prescriptions and the history of receipt of such patient-specific prescriptions for that drug product over any consecutive 14-day period within the previous 6 months (Guidance for Industry (Draft) (\#230) 2015). Some veterinary state boards already restrict having compounded drugs from a compounding pharmacy kept at the veterinarian clinic for "office use" (State of the State of Drug compounding on Minnesota). For the compounding pharmacist, documentation is needed that the compounded drug cannot be made from the FDA-approved drug(s). For example, if a manufacturer discontinues a product or a prolong shortage is expected but the specific animal medication need still exist. Other cases may include the pharmacist noting a potential physicochemical incompatibility when the approved product is to be mixed or diluted with other ingredients per the veterinarian prescription. The pharmacy should confirm that compounded drug is not intended for use in foodproducing animals by checking that the prescription or accompanying document contains the statement "This patient is not a food-producing animal". The new guidance will require both the compounding pharmacist and the prescribing veterinarian to engage in more communication/coordination which is to the benefit of the animal patient. It should be noted that many of the conditions set by FDA are standard practice that most compounding facilities would be expected to be observing including good compounding practices, code of ethics (Code of ethicsInternational Academy of Compounding) and operating in accordance with USP/NF Chapters $<795>$ and $<797>$.

\section{Conclusions}

It is the hope that once populated with bulk drug substances, Appendix A would reflect a comprehensive and diverse list of bulk drug substances from which compounded products can offer therapies that are currently not available to animal patients. Personalized medicine should not be a theme restricted to the human 
population. Outsourcing facilities serving the compounding needs for the veterinary patient play an important role in providing optimal pharmaceutical care in that special population.

\section{Competing interests}

The author declares that he has no competing interests.

Received: 1 March 2016 Accepted: 28 May 2016

Published online: 07 July 2016

\section{References}

Chan DS (2001) Regulatory issues for the use of bulk drugs in veterinary compounding. IJPC 5(2):97-100

Code of ethics- International Academy of Compounding. http://www.iacprx.org/?6. Accessed 28 Feb 2016

Davis JL (1997) Marketing to veterinarians. IJPC 1(4):236-240

FD\&C Act Chapter V: Drugs and Devices http://www.fda.gov/Regulatory Information/Legislation/FederalFoodDrugandCosmeticActFDCAct/ FDCActChapterVDrugsandDevices/. Accessed 28 Feb 2016

Guidance for Industry (Draft) (\#230): "Compounding Animal Drugs from Bulk Drug Substances" May 19, 2015. http://www.fda.gov/ucm/groups/fdagovpublic/@fdagov-av-gen/documents/document/ucm446862.pdf. Accessed 28 Feb 2016

Guidance for industry: "Fees for Human Drug Compounding Outsourcing Facilities Under Sections 503B and 744K of the FD\& C Act", November 2014. http://www.fda.gov/downloads/Drugs/ GuidanceComplianceRegulatoryInformation/Guidances/UCM391102.pdf accessed 28 Feb 2016

Lecuyer M, Prini S, Dunn ME, Doucet MY (2006) Clinical efficacy and safety of transdermal methimazole in the treatment of feline hyperthyroidism. Can Vet J 47:131-135

Sartor LL, Trepanier LA, Kroll MM, Rodan I, Challoner L (2004) Efficacy and safety of transdermal methimazole in the treatment of cats with hyperthiodism. J Vet Intern Med 18:651-655

State of the State of Drug compounding on Minnesota. https://mn.gov/boards/ assets/Spring\%202014\%20Newsletter_tcm21-26525.pdf. Accessed 29 Feb 2016

Steinschneider J. Compounding regulatory perspective. Office of surveillance \& compliance, FDA, Center for veterinary medicine. USP Veterinary Drugs Stakeholder Forum November 9, 2012. http://www.usp.org/sites/default/files/ events/stakeholder_forums/2012/meeting-1/6a-animal-drug-compoundingfda-perspective-2012-11-09.pdf. Accessed 28 Feb 2016

\section{Submit your manuscript to a SpringerOpen ${ }^{\circ}$ journal and benefit from:}

- Convenient online submission

- Rigorous peer review

- Immediate publication on acceptance

- Open access: articles freely available online

- High visibility within the field

- Retaining the copyright to your article 